\title{
A 15-year retrospective review of urodynamic studies in children at Red Cross War Memorial Children's Hospital, Cape town, South Africa
}

Thembisile Dintle Mosalakatane ( $\sim$ dintletn@yahoo.com )

University of Cape Town Institute of Child Health: University of Cape Town Department of Paediatrics and Child Health https://orcid.org/0000-0001-5871-0345

Anne Wright

Evelina London Children's Hospital

Jeanette Raad

Red Cross War Memorial Children's Hospital

John Lazarus

Red Cross War Memorial Children's Hospital

Justin Howlett

Red Cross War Memorial Children's Hospital

Mignon McCulloch

Red Cross War Memorial Children's Hospital

Peter Nourse

Red Cross War Memorial Children's Hospital

Ashton Coetzee

Red Cross War Memorial Children's Hospital

\section{Research Article}

Keywords:

Posted Date: February 22nd, 2022

DOI: https://doi.org/10.21203/rs.3.rs-1365609/v1

License: (c) (i) This work is licensed under a Creative Commons Attribution 4.0 International License.

Read Full License 


\section{Abstract}

\section{Background:}

Despite the undeniable diagnostic benefits of urodynamic studies (UDS), their adoption into clinical practice in Africa has been slow. This study aimed to review the use of invasive UDS in children at a tertiary paediatric hospital in South Africa.

\section{Methods:}

A retrospective analysis of 1108 UDS was conducted. Patient demographic characteristics, primary diagnosis, indication and urodynamic outcomes were reviewed. Presence of urodynamic high-risk features were documented, and a comparison was made between the first study and follow-up study.

\section{Results:}

This study revealed increasing trends in the use of UDS from 2015. Referrals were from Urology (37.7\%), Spinal defects clinic (34.4\%), Nephrology (20.8\%) and other departments $(7.0 \%)$. The most common reason for referral was review of medical treatment (36.5\%). Spinal dysraphism (58.3\%) accounted for the majority of conditions seen. Majority $(59.1 \%)$ of the patients were receiving more than one type of bladder treatment at the time of their first study, with clean intermittent catheterisation (46.5\%) being the most common form of bladder management. $97.5 \%$ of studies were performed using transurethral bladder catheterization. Urodynamic diagnosis was neurogenic in $74.0 \%$, anatomical (12.2\%), functional (8.8\%) and normal (5.0\%). There was statistically significant improvement in bladder compliance, detrusor leak point pressure and detrusor sphincter dyssynergia between the first study and a subsequent study following therapeutic intervention.

\section{Conclusion:}

The unique ability of UDS to demonstrate changes in detrusor pressures, which is a common reason for therapy failure, makes UDS an invaluable tool in the diagnosis and management of children with lower urinary tract dysfunction.

\subsection{Introduction}

Lower urinary tract dysfunction (LUTD) is a common problem causing a major social and psychological burden to both children and their families. If left untreated, some cases of LUTD such as anatomic, neurogenic or severe dysfunctional voiding, may cause irreversible kidney damage. The goal of treatment is therefore aimed at protecting the kidneys and ensuring urinary continence, with direct positive effects for the child's quality of life [1]. The treatment of LUTD greatly depends upon establishing the correct diagnosis. The complex and multifactorial nature of LUTD at times makes it difficult to diagnose and treat. Traditionally, the evaluation of a child with LUTD includes a history, physical examination, bladder and stool diaries, kidney-ureter-bladder (KUB) ultrasonography and voiding cystourethrogram (VCUG). 
Unfortunately, there is a sizable proportion of patients in whom conventional approaches fail to provide an explanation of their symptoms.

Urodynamic study (UDS) is an emerging modality in paediatric practice that has been used to identify other lower urinary tract (LUT) pathologies where conventional modalities have failed to establish a diagnosis. The major benefit of UDS is its ability to assess the mechanical function of the bladder, sphincter and urethra [2]. These tests are either invasive or non-invasive. Invasive UDS has an advantage over other modalities as the only investigation that is able to assess detrusor pressures during bladder filling and voiding phases. A video urodynamic study (VUDS) is an all-in-one invasive UDS which combines the standard UDS with a VCUG. When VUDS is performed, information on both mechanical function and anatomy of the LUT can be obtained $[2,3]$. There is compelling data that support its use in patients with neurogenic lower urinary tract dysfunction (NLUTD) $[4,5]$. The International Children's Continence Society (ICCS) now recommends UDS (preferentially VUDS) for all children with spinal dysraphism and those with suspected neurogenic bladder from other causes [4]. Several institutions have now begun to adopt universal rather than risk stratified UDS protocols for children with spinal dysraphism [6].

Invasive UDS is not without its own inherent problems. It involves bladder catheterization, which may cause discomfort and anxiety in a child. Many authors do not recommend its routine use in assessing children with non-neurogenic lower urinary tract dysfunction (NNLUTD) [7, 8]. They argue that UDS does not generally change the management and treatment in these patients, as in most cases a detailed voiding history and physical examination is usually sufficient for a correct diagnosis [7, 8]. It is therefore, suggested that, in these types of patients, UDS be reserved for children who are failing standard therapy or where conventional investigations have failed to provide answers for their symptoms [9]. Some authors support its use in the evaluation of children with recurrent urinary tract infections (UTI) associated with history of voiding dysfunction (frequency, urgency and incontinence) $[10,11]$.

As the role and demand of UDS in both paediatric urology and nephrology increases, several studies have exposed gaps in the literature relating to method of bladder catheterisation (transurethral vs suprapubic) and type of anaesthesia (local vs general) when performing the study, and definition of high-risk features for kidney damage $[2,12-14]$. There is also lack of data in the use of UDS in the African context, and current knowledge on urodynamic investigations in the African paediatric population is mainly based on studies done in Europe, North America and Asia. This study was undertaken to describe the 15-year experience with the use of invasive urodynamic studies conducted at Red Cross War Memorial Children's Hospital (RCWMCH), Cape Town, South Africa during the period September 2005 to September 2020.

The specific objectives for this study are:

1. To identify the common indications for urodynamic studies at RCWMCH.

2. To determine the prevalence and aetiology of both non-neurogenic and neurogenic lower urinary tract dysfunction in children undergoing urodynamics investigation at RCWMCH. 
3. To determine the proportion of patients with active bladder interventions such as clean intermittent catheterization (CIC), antimuscarinic/ anticholinergic medication, intravesical Botox injection, Deflux ${ }^{\circledR}$ (Hyaluronic acid/Dextranome)/STING (subureteral Teflon injection) procedure, ureteral reimplantation and bladder augmentation.

4. To determine the proportion of patients with high-risk features [low bladder compliance, detrusor leak point pressure (DLPP) $\geq 30 \mathrm{~cm} \mathrm{H}_{2} \mathrm{O}$, presence of neurogenic detrusor overactivity (NDO), presence of detrusor sphincter dyssynergia (DSD)] for upper urinary tract damage.

\subsection{Materials And Methods}

\subsection{Study site}

The RCWMCH Urodynamics \& Manometric Unit was established in September 2005. Initially the unit provided services mainly to the Spinal Defect Clinic. The unit has expanded over the years to include investigation of children with LUTD due to causes other than spinal dysraphism. Services offered include Uroflowmetry, Urodynamics, Video Urodynamics, Ambulatory Urodynamics, pH Impedance Studies, and Anorectal Manometry. Urodynamic testing is performed by a trained medical technologist, who has undergone training in urodynamics. Until the year 2016, the studies were performed using the Medtronic Urodynamic Measurement System. The urodynamic studies are now performed using the Nexam Pro Urodynamic System. It is the standard practice of the hospital to perform UDS following the ICCS good urodynamic practices [12]. All studies are performed and interpreted by a urodynamic technologist and reviewed by an experienced urologist. Complex cases or inconclusive studies are usually discussed during weekly combined (radiology, urology and nephrology) meetings.

\subsection{Study population}

This work covers a fifteen-year period from September 2005 to September 2020. Included in this study are all patients who underwent invasive UDS at RCWMCH during the study period. Patients were excluded from the analysis if studies were partially completed or in cases where data was missing from their records.

\subsection{Data collection}

From the request form completed by the referring clinician the following demographic and clinical information was retrieved: 1) patient demographic data at the time of UDS (age, sex,); 2) referring speciality; 3 ) the type of study (first study or follow-up); 4) primary diagnosis; 5) reason for referral; and 6) patient's current treatment (CIC, pharmacological, surgical). Missing data was accessed through the patient's hospital record. The UDS report for each patient was then reviewed and the following data was recorded. 1) Maximum cystometric capacity (expressed as \% of expected bladder capacity); 2) presence of high risk features (low bladder compliance, DLPP $\geq 30 \mathrm{~cm} \mathrm{H}_{2} \mathrm{O}, \mathrm{NDO}, \mathrm{DSD}$ ); and 3) VUR. The UDS findings were classified into normal, neurogenic, functional and anatomical. Study data was collected 
and managed using REDCap electronic data capture tools hosted at University of Cape Town (redcap@uct.ac.za).

\subsection{Definitions}

Terminology adheres to standards recommended by the ICCS except where specifically noted[13]. End-fill detrusor pressure (EFP): The baseline detrusor pressure recorded at the end of the filling phase, prior to commencement of voiding.

Low bladder compliance is defined as EFP greater than $20 \mathrm{~cm} \mathrm{H}_{2} \mathrm{O}$ (baseline detrusor pressure at the end of cystometry filling in the absence of detrusor overactivity) as a cut-off point. There are no standardised normal values for calculated compliance in children. This is because normal bladder capacity increases with age. This is lower than the most frequently quoted risk level of $40 \mathrm{~cm} \mathrm{H}_{2} \mathrm{O}$. Of recent, many clinicians are revising this cut-off value and considering lower cut-off values to facilitate the chance of reversibility with treatment.

Expected bladder capacity (EBC): EBC was calculated from the Hjalmas equation [EBC = age (years) $\times 30$ +30 (expressed in $\mathrm{m})$ ] [12].

Definition of vesicoureteral reflux (VUR) is according to the International System of Radiologic Grading of VUR [15]:

I. High grade VUR: Refers to grade IV and V VUR

II. Low grade VUR: Refers to grade I, II and III VUR

\subsection{Data analysis}

The analysis was performed using IBM Statistical Package for Social Sciences (SPSS) Statistics for Windows, Version 27.0. Before data analysis was carried out, the data was thoroughly cleaned and consistency checks made on each variable several times in order to ensure that all the data or major points under each had been captured. Continuous variables were expressed as range and median and the categorical variable as proportions $n(\%)$. $p$ values were calculated by, $\chi$. test, or Fisher's exact test, as appropriate. p-value of 0.05 was considered statistically significant

\subsection{Ethical approval}

Ethical approval for this study was obtained from Human Research Ethics Committee, University of Cape Town (HREC REF: 461/2020) and Research Review Committee, Red Cross War Memorial Children's Hospital (RXH: RCC 239).

\subsection{Results}




\subsection{Study population and demographic characteristics}

During the period under review, 1127 invasive urodynamic studies performed at RCWMCH were identified. As shown in Fig. 1, exclusions were predominantly incomplete studies due to machine malfunctioning (7/1127), power cuts (1/1127), difficult urethral catheterisation (4/1127) and an uncooperative child (5/1127). Only 2/1127 cases were excluded for lack of complete clinical and/or UDS data. This number may not be a true reflection of the total number of incomplete studies as unsuccessful studies conducted during the initial setup phase of the urodynamic unit were not recorded. Primary analyses were performed using 1108 UDS studies: 646 (58.3\%) male patients and 462 (41.7\%) female patients. They had a median age of 7.0 years (IQR) at time of study (see Table 1).

\subsection{Trend in the number of invasive urodynamics studies performed}

Between 2005 and 2014, 592 studies were performed (mean, 59 per year). There is variation in the number of studies performed annually (see Fig. 2 ). This variation in UDS quantity has been influenced by several factors including delays and interruptions caused by servicing of machine in 2009, unit renovations between 2013 and 2014, and more recently Covid-19 pandemic in 2020. Although there is variation in quantity of UDS performed per year, on average the number of studies increased from 2015 through 2019 (mean, 90 per year).

\subsection{General characteristics of children}

Table 1 also summaries the clinical characteristics and indication for UDS. The most frequent conditions seen included spinal dysraphism (myelomeningocele, myelocele, lipomyelocele, disatematomyelia) 646 (58.3\%), PUV 153(13.8), sacral agenesis 57(5.1\%), anorectal malformation 54 (4.9\%), acquired spinal abnormalities (trauma, infections etc.) 52 (4.7\%) enuresis 49 (4.4\%), primary VUR (1.5\%), and other conditions (13.0\%). More than one condition per patient could be present, for instance, a patient with spinal dysraphism could also have anorectal malformation. Referrals were received from various departments, the majority coming from the Urology department (37.7\%). The other sources of referral were Spinal defect clinic (34.4\%), Nephrology (20.8\%) and other departments (neurology, neurosurgery, oncology, other hospitals) $(7.0 \%)$. The most common reason stated in the referral was review of medical treatment (36.5\%).

Table 1 Demographic and clinical information in children referred for urodynamic studies 


\begin{tabular}{|c|c|c|}
\hline Variable & $n$ & $\%$ \\
\hline \multicolumn{3}{|l|}{ Sex } \\
\hline Male & 646 & 58.3 \\
\hline Female & 462 & 41.7 \\
\hline \multicolumn{3}{|l|}{ Age (years) } \\
\hline Median (IQR) & $7.0(4.0-11.0)$ & \\
\hline \multicolumn{3}{|l|}{ Type of study } \\
\hline First study & 727 & 65.6 \\
\hline Follow-up study & 381 & 34.4 \\
\hline \multicolumn{3}{|l|}{ Referral } \\
\hline Spinal Defect Clinic & 381 & 34.4 \\
\hline Urology & 418 & 37.7 \\
\hline Nephrology & 231 & 20.8 \\
\hline Other departments & 78 & 7.0 \\
\hline \multicolumn{3}{|l|}{ Primary Diagnosis[a] } \\
\hline Spinal dysraphism & 646 & 58.3 \\
\hline Acquired spinal abnormalities & 52 & 4.7 \\
\hline Anorectal Malformation & 54 & 4.9 \\
\hline Sacral agenesis & 57 & 5.1 \\
\hline PUV & 153 & 13.8 \\
\hline Primary VUR & 17 & 1.5 \\
\hline Enuresis & 49 & 4.4 \\
\hline Other & 144 & 13.0 \\
\hline \multicolumn{3}{|l|}{ Indication for UDS[b] } \\
\hline Baseline & 116 & 10.5 \\
\hline Recurrent UTI & 206 & 18.6 \\
\hline VUR & 124 & 11.2 \\
\hline Recurrent UTI + VUR & 109 & 9.9 \\
\hline Review medical therapy & 404 & 36.5 \\
\hline Review surgical treatment & 94 & 8.5 \\
\hline
\end{tabular}




\begin{tabular}{|ccc|} 
Pre-surgical intervention & 63 & 5.7 \\
Pre-transplant & 43 & 3.9 \\
Post-transplant & 34 & 3.1 \\
Other & 51 & 4.6 \\
\hline
\end{tabular}

[a] Some children had multiple conditions

[b] Some children had multiple indications

IQR-interquartile range

\subsection{Types of bladder intervention at first study}

As shown in Fig. 3, a significant number of patients were already receiving some form of bladder intervention before their first UDS. The majority of the patients were receiving more than one type of bladder treatment $430(59.1 \%)$. Of the 3 types of treatment (CIC, medical and surgical), CIC $338(46.5 \%)$ was found to be the most common form of bladder management. 297 (40.9\%) of the patients were not on any therapy at the time of their first UDS.

\subsection{Method of bladder catheterisation}

Almost all (97.5\%) of the patients had bladder catheters inserted urethrally (see Fig. 4). Other methods of bladder catheterization were used if the patient was already using the technique for bladder emptying.

\subsection{Urodynamic outcomes}

The urodynamic diagnosis was neurogenic in 820 (74.0\%), anatomical 135 (12.2\%), functional 98 (8.8\%) and normal 55 (5.0\%). Table 2 shows the distribution of urodynamic data of the 4 groups. There was no significant age difference in all the 4 groups. Although the majority of the studies were performed in males, there was a female (69.4\%) predominance in those with functional LUTD. Almost all those with anatomical LUTD were males (97.0\%). UDS revealed low bladder compliance in $44.4 \%$ of all studies. Detrusor overactivity was recorded in $14.4 \%$ of UDS. VUR was detected in 54 out of 168 (32\%) VUDS.

\subsection{High risk features for upper tract damage}

With the exception of neurogenic detrusor overactivity $(p=0.48)$, there was statistically significant improvement in low bladder compliance $(p<0.001)$, detrusor leak point pressure $>30 \mathrm{~cm} \mathrm{H} 20(p<0.001)$ and detrusor sphincter dyssynergia $(p=0.03)$ between the first study and the study following therapeutic intervention (Fig. 5). 
Table 2. Urodynamic outcomes

Page 9/22 


\begin{tabular}{|c|c|c|c|c|c|}
\hline \multirow[t]{2}{*}{ Variable } & \multirow{2}{*}{$\begin{array}{l}\text { Total (\%) } \\
n=1108\end{array}$} & \multirow{2}{*}{$\begin{array}{l}\text { Normal } \\
(\%) \\
n=55\end{array}$} & \multirow[t]{2}{*}{$\begin{array}{l}\text { Neurogenic } \\
\text { (\%) } n=820\end{array}$} & \multirow{2}{*}{$\begin{array}{l}\begin{array}{l}\text { Functional } \\
(\%)\end{array} \\
n=98\end{array}$} & \multirow{2}{*}{$\begin{array}{l}\begin{array}{l}\text { Anatomical } \\
(\%)\end{array} \\
n=135\end{array}$} \\
\hline & & & & & \\
\hline \multicolumn{6}{|l|}{ Age (years) } \\
\hline Median (IQR) & $\begin{array}{l}7.0(4.0- \\
11.0)\end{array}$ & $\begin{array}{l}6.0(1.0- \\
10.0)\end{array}$ & $7.0(4.0-11.0)$ & $\begin{array}{l}8.0(6.0- \\
11.0)\end{array}$ & $8.0(5-11.0)$ \\
\hline \multicolumn{6}{|l|}{ Sex } \\
\hline Male & $646(58.3)$ & $36(65.5)$ & $449(54.8)$ & $30(30.6)$ & 131(97.0) \\
\hline Female & $462(41.7)$ & $19(34.5)$ & $371(45.2)$ & $68(69.4)$ & $4(3.0)$ \\
\hline \multicolumn{6}{|l|}{$\begin{array}{l}\text { Incontinence pattern after } \\
\text { age } 5 \text { years }[1]\end{array}$} \\
\hline \multicolumn{6}{|l|}{ Day time } \\
\hline Night-time & $422(53.9)$ & $16(29.0)$ & $329(40.1)$ & $40(40.8)$ & $38(28.1)$ \\
\hline \multirow{2}{*}{ Both } & $460(58.8)$ & 18(32.7) & $353(43.0)$ & $45(45.9)$ & $43(31.9)$ \\
\hline & $490(62.6)$ & $20(36.3)$ & $374(45.6)$ & $49(50.0)$ & $49(36.3)$ \\
\hline \multicolumn{6}{|l|}{$\begin{array}{l}\text { Maximum cystometric } \\
\text { capacity (\% of EBC) }\end{array}$} \\
\hline \multicolumn{6}{|l|}{ Small $(<65 \%)$} \\
\hline Normal (65-150\%) & $3 \angle 3(29.1)$ & $3(0.5)$ & $215(33.5)$ & $30(30.6)$ & $1 /(12.0)$ \\
\hline \multirow{2}{*}{ Large $(>150 \%)$} & $680(62.3)$ & $52(94.5)$ & $486(59.2)$ & $47(48.0)$ & $95(70.4)$ \\
\hline & $87(8.0)$ & - & $53(6.5)$ & 13(13.2) & $21(15.6)$ \\
\hline Low bladder compliance & $492(44.4)$ & - & $420(51.2)$ & $20(20.4)$ & $52(38.5)$ \\
\hline \multicolumn{6}{|l|}{ Detrusor activity } \\
\hline Overactive & $163(14.8)$ & - & $87(10.6)$ & $50(51.0)$ & 26(19.3) \\
\hline Underactive & $50(4.5)$ & - & $26(3.2)$ & $20(20.4)$ & $4(3.0)$ \\
\hline \multicolumn{6}{|l|}{ VUR } \\
\hline High & $41(3.7)$ & - & $21(2.6)$ & $5(5.1)$ & 15(11.1) \\
\hline Low & $13(1.2)$ & - & $8(1.0)$ & $4(4.1)$ & $1(0.7)$ \\
\hline
\end{tabular}


[1] $n=782, E B C=$ [age (years) $\times 30+30$ (expressed in $\mathrm{ml})]$ for those $>2$ years old and [ $7 \times$ weight $(\mathrm{kg})$ expressed in $\mathrm{ml}$ )] for those $<2$ years old

\subsection{Discussion}

The use of urodynamic studies in children has become increasingly popular in recent years, however there is limited literature concerning its use in sub-Saharan Africa. This study is a description of a 15-year experience with 1108 invasive urodynamic studies performed at Red Cross War Memorial Children's Hospital between September 2005 and September 2020. The most important findings of this study are the following: (1) the increasing trends in the use of UDS from 2015; (2) the wide range of indications for urodynamic testing; (3) presence of high risk urodynamic features at first study despite having previously been evaluated using the conventional modalities and receiving multiple bladder treatments; (4) a statistically significant improvement between first time study and follow-up study (post interventional) using low bladder compliance, detrusor sphincter dyssynergia (DSD) and detrusor leak point pressure (DLLP) $>30 \mathrm{~cm} \mathrm{H}_{2} \mathrm{O}$; and (5) the study also revealed the difficulties in treatment and management of children with LUTDs which may necessitate that multiple follow-up studies be carried to monitor response.

In the present study, the majority (58.3\%) of UDS were performed on male patients with a median age at first study of 7.0 years (range 4.0-11.0 years). A similar sex difference was also reported by Hoebeke et al and Swithinbank et al. $[11,14]$. The observed male predominance can be explained by the fact that LUTDs such as PUV, which accounted for $13.8 \%$ of all studies, only occur in male patients. Studies with a female predominance were mainly focusing on the use of UDS in children with NNLUTD such has urge syndrome, dysfunctional voiding etc $[8,9,16]$.

The 15-year results showed increasing trends in the use of UDS. The observed upward trend from 2015 can be explained by the increase of knowledge surrounding the advantages of using the urodynamic studies when evaluating children with LUTD. Previous research corroborates the benefits of utilizing UDS for the diagnosis and management of children with neurogenic lower urinary tract dysfunction, including its superiority over traditional diagnostic modalities $[5,17-20]$. When evaluating 51 patients with closed spina bifida, Johnston et al. demonstrated that clinical neurological assessment, history of voiding habit and renal tract ultrasonography were not reliable indicators of bladder dysfunction compared to VUDS [5]. Tarcan et al. reported that newborns with myelodysplasia and normal bladder function on urodynamics still require follow-up urodynamic testing [17]. They also reported a $32 \%$ risk for urodynamic deterioration [17]. Several guidelines including the ICCS, European Association of Urology and the European Society for Paediatric Urology (EAU/ESPU) recommend urodynamic testing for all children with suspected neurogenic lower urinary tract dysfunction $[4,6]$.

Because of this compelling data on UDS in children with NLUTD, it is not surprising that the majority (62.1\%) of urodynamic testing in this study were of children with spinal abnormalities. These included spinal dysraphism (myelomeningocele, myelocele, lipomyelocele, disatematomyelia) (52.3\%), acquired 
spinal abnormalities (trauma, infections, metabolic and neoplasm) (4.7\%) and sacral agenesis (5.1\%). There may be a preferential referral from the multidisciplinary Spinal Defect Clinic at RCWMCH as the Urologists are the primary discipline at these clinics. A total of $37.7 \%$ studies performed were requested by the Urology department. There also seem to be a fair number of referrals coming from other departments, Spinal defect clinic 34.4\%, Nephrology 20.8\% and other (Oncology, Neurology, Neurosurgery, other hospitals) $7.0 \%$. This finding suggests that the value of UDS has received heightened awareness even in specialties that have historically not involved it. Another notable finding is the small number 49 (4.4\%) of patients referred with enuresis as an indication. This might be due to the fact that the centre currently has a tendency of undertaking uroflowmetry first for all functional LUTD and reserving invasive studies for patients not responding to treatment.

The justification for an invasive urodynamic study request is normally based on the assumption that the outcome is likely to affect treatment, when treatment does not lead to its intended outcome or when surgical interventions are planned $[7,10,12,21]$. The benefits of performing a UDS should also outweigh the risks. The indications for the UDS studies performed are listed in Table 1. The most common reason for UDS were to discern treatment effects (medical 36.5\% and surgical 8.5\%). The study revealed that at first urodynamic study, $59.1 \%$ of children were already receiving more than one type of bladder management. It is evident from this finding that LUTD can be difficult to treat and often requires more than one type of bladder treatment. This observation also raises a concern of delayed referral for some patients. The ICCS advocates a baseline UDS before the age of one year for all patients with spinal dysraphism, even before symptoms start [4]. Early intervention is necessary to decrease significant complications such as end stage kidney disease in these cases. To improve early referral, there should be continued medical education on UDS and quality improvement projects. CIC appears to be the most commonly used method of treatment. This reflects the hospital's institutional practice of CIC initiation in spinal dysraphism patients at an early age. The most frequently prescribed drug for bladder management was Oxybutynin (305 of 727), compared to Solifenacin succinate (9 of 727) and Mirabegron not being used in any patients in our study. Drug availability and cost might have influenced the choice of medication prescribed. Both Mirabegron and Solifenacin succinate were not available for use in our hospital during the study period as they are not on the drug formulary mainly due to their high cost. However, patients under medical aid cover were able to purchase the medications from private pharmacies.

The remaining UDS were ordered for recurrent UTI (18.6\%), VUR (11.2\%), baseline study (10.5\%), recurrent UTIs associated with VUR (9.9\%), pre- and post-transplant (7.0\%), pre- surgical intervention (5.7\%) and anorectal malformation (4.9\%). The clinical significance of invasive UDS in children with NNLUTD still remain the source of controversy in literature $[7,9,10]$. Soygür et al. retrospectively evaluated the role of VUD in the diagnosis and management of voiding dysfunction and found that VUDS did not generally change approach to the patient [7]. In a multicentre controlled trial in children with urge syndrome and dysfunctional, Bael et al. recommends reserving VUD for those who have failed initial treatment [9]. Glazier et al. demonstrated abnormal VUDS in 28 out of 38 children with recurrent UTIs associated with voiding dysfunction [10]. In their study only 5 out of 38 had abnormal VCUG and KUB. From their study 
they strongly recommend VUDS to be considered in children with recurrent UTIs and a history of voiding dysfunction [10]. To address the current controversies in the additional value of UDS in children with NNLUTD, ICCS advocates for urodynamic testing in children with NNLUTD only if it will guide treatment plans and procedures [12].

There is controversy surrounding the method of bladder catheterization when performing a urodynamic examination. The concern regarding transurethral catheters is that it can affect urethral function and increase leak point pressure (LPP). However, several studies have demonstrated that the use of catheterization does not alter urethral function [22-24]. One such study is by Spinoit et al. which showed that transurethral catheters performed in a child-friendly outpatient clinic provides useful urodynamic information [23]. Most recently, Janssen et al. when comparing suprapubic and transurethral catheters to test urethral pressures in rats found no difference [24]. The ICCS Standardization Report on Urodynamic Studies of the Lower Urinary Tract in Children recommends the use of either methods; however, risks should be weighed against benefit when the suprapubic route is used. In this study almost all (97.5\%) urodynamic studies were performed with either a $6 \mathrm{~F}$ or $7 \mathrm{~F}$ double lumen transurethral catheters. Voiding phase is often assessed by performing a uroflow first and removal of the catheter after an invasive study, however this study did not determine the number of UDS where the voiding phase was assessed this way. The main reason for those performed using either Mitrofanoff $(1.1 \%)$ or suprapubic catheter $(1.4 \%)$ was because the patients were already using the technique for bladder emptying. The use of suprapubic catheterization is not a feasible option in a resource limited setting as it requires hospital admission with theatre time and monitoring space.

Although UDS usage has increased, concerns have been raised that the use of invasive urodynamic testing is not always justified in some patients. Only $5.0 \%$ of studies were reported as normal and this finding may reflect the appropriate use of UDS in children. This is comparable to Hoebeke et al and Johnston et al who reported $6 \%$ and $8 \%$ of normal studies respectively $[5,11]$. Glazier et al. reported much higher incidence of normal studies when evaluating the utility of VUD in 42 children with UTI and voiding dysfunction [10]. Even though a significant number (430 of 727) of children were receiving more than on type of bladder treatment at first study, the study revealed low bladder compliance (278 of 727), DLPP $>30 \mathrm{~cm} \mathrm{H}_{2} \mathrm{O}$ (160 of 727), neurogenic detrusor overactivity (54 of 727) and DSD (26 of 727). This reflects the difficulties in treating some of these patients and that UDS is often warranted to facilitate more specific diagnoses and guide treatment. The higher incidence of low bladder compliance (420 of 820), in those with NLUTD represents the importance of UDS in all patient with suspected NLUTD to identify those at risk for problems. ICCS advocates early urodynamic profiling in these patients and follow-up studies to allow early intervention and decrease significant complications. In this study the incidence of VUR could only be determined after introduction of VUDS, from year 2017. VUR was detected in 54 out of $168(32 \%)$ VUDS. This study did not differentiate whether VUR was primary or secondary.

The clinical significance of performing a urodynamic testing has been demonstrated in this study. The overall goal of treatment of children with LUTDs is to preserve upper tracts and ameliorate or delay progression to ESKD especially in a setting where dialysis and transplantation may not be easily 
available. From the literature, factors associated with upper tract damage are low bladder compliance, $D S D$, neurogenic detrusor overactivity (NDO) and $D L P P>40 \mathrm{~cm} \mathrm{H}_{2} \mathrm{O}$. With the exception of NDO $(\mathrm{p}=0.48)$, there was significant statistical improvement between the first study and follow-up study using low bladder compliance $(p<0.001), D L P P>30 \mathrm{~cm} \mathrm{H}_{2} \mathrm{O}(p<0.001)$ and DSD $(p=0.03)$. Based on this finding, the use of urodynamic examination in children with LUTDs has the potential to lower the incidence rate of renal replacement therapy.

The strength of this study is that it represents the largest number of invasive urodynamic studies in SubSaharan region. Another strength of this study is that it has defined variables using the ICCS definitions allowing comparison with other similar studies. It included a wide array of clinical indications and broader range of diagnosis. This study also included a diverse set of referring specialities. Nevertheless, this study is not without limitations. This was a single centre study but with large numbers. Other limitations relate to its retrospective design. Some UDS were excluded because of missing data and some studies may have been missed. Also, the incidence of DSD and VUR reported in this study may have been underestimated as they were periods where the centre was unable to perform electromyography and the use of VUDS started after year 2017.

In conclusion, this study has demonstrated an increased interest in the use of UDS in children. It has shown that UDS can guide in selecting most appropriate treatments for children with LUTD. It has highlighted the difficulties in the management of children with LUTDs which may necessitate that multiple follow-up studies be carried to monitor response. The recommendation of early and frequent follow-up UDS for children with spinal dysraphism recommended by ICCS may not be feasible in a resource limited country. For Africa this may mean early start on $\mathrm{CIC}$, prioritizing patients based on their risk for upper tract damage and effective application of bladder and stool diaries, KUB (pre- and post-void residual volume) ultrasonography and VCUG.

\section{Abbreviations}

CIC Clean Intermittent Catheterisation

DSD Detrusor Sphincter Dyssynergia

EAU European Association of Urology

EBC Expected Bladder Capacity

EFP End-Fill Detrusor Pressure

ESPU European Society for Paediatric Urology

ESKD End Stage Kidney Disease

ICCS International Children's Continence Society

Page 14/22 
IQR Interquartile Range

KUB Kidney-Ureter-Bladder

DLPP Detrusor Leak Point Pressure

LUTD Lower Urinary Tract Dysfunction

NDO Neurogenic Detrusor Overactivity

NLUTD Neurogenic Lower Urinary Tract Dysfunction

NNLUTD Non-Neurogenic Lower Urinary Tract Dysfunction

PUV Posterior Urethral Valves

RCWMCH Red Cross War Memorial Children's Hospital

SPSS Statistical Package for Social Sciences

TUC Transurethral Catheterisation

UDS Urodynamic Study

UTI Urinary Tract Infection

VCUG Voiding Cystourethrogram

VUDS Video Urodynamic Study

VUR Vesicourethral Reflux

\section{Declarations}

\section{Acknowledgements}

We would like to acknowledge the extraordinary work by Mrs. Jeanette Raad in performing the urodynamic studies at Red Cross War Memorial Children's Hospital since the establishment of the Unit in September 2005 to date. We are grateful to the hardworking and caring doctors and nurses who cared for these patients. The contribution of Mr. Wisdom Basera for his expert advice and guidance on statistical analysis is highly appreciated. Special thank you to Dr Nonofo Ditshego for his support.

\section{Funding}

No funding was received for conducting this study. 
Approval was obtained from the Human Research Ethics Committee, University of Cape Town (HREC REF: 461/2020) and Research Review Committee, Red Cross War Memorial Children's Hospital (RXH: RCC 239).

\section{Conflict of interest}

There is no conflict of interest to declare.

"This work has been made possible through my ISN-IPNA funded Fellowship".

\section{References}

1. Cameron AP. Medical management of neurogenic bladder with oral therapy. Translational Androl Urol. 2016;5:51.

2. Homma Y, Batista J, Bauer S, Griffiths D, Kramer G, Lose G. Rosier P Committee 7.

3. Jehle K, Lazarus J, Raad J. Neurogenic lower urinary tract dysfunction: the role of urodynamics. CME: Your SA Journal of CPD. 2012;30:166-70.

4. Bauer SB, Austin PF, Rawashdeh YF, de Jong TP, Franco I, Siggard C, Jorgensen TM. International Children's Continence Society's recommendations for initial diagnostic evaluation and follow-up in congenital neuropathic bladder and bowel dysfunction in children. Neurourol Urodyn. 2012;31:6104.

5. Johnston L, Borzyskowski M. Bladder dysfunction and neurological disability at presentation in closed spina bifida. Arch Dis Child. 1998;79:33-8.

6. Stein R, Bogaert G, Dogan HS, Hoen L, Kocvara R, Nijman RJ, Quadackers JS, Rawashdeh YF, Silay MS, Tekgul S. EAU/ESPU guidelines on the management of neurogenic bladder in children and adolescent part I diagnostics and conservative treatment. Neurourol Urodyn. 2020;39:45-57.

7. Soygür T, Arikan N, Tokatli Z, Karaboga R. The role of video-urodynamic studies in managing nonneurogenic voiding dysfunction in children. BJU Int. 2004;93:841-3.

8. Conkar S, Mir S. Are Urodynamic Studies Really Necessary in Voiding Dysfunction in Children? Haseki Tip Bulteni. 2018;56:192.

9. Bael A, Lax H, de Jong TP, Hoebeke P, Nijman RJ, Sixt R, Verhulst J, Hirche H, van Gool JD, † EBDS. The relevance of urodynamic studies for Urge syndrome and dysfunctional voiding: a multicenter controlled trial in children. J Urol. 2008;180:1486-95.

10. Glazier D, Murphy D, Fleisher M, Cummings K, Barone J. Evaluation of the utility of videourodynamics in children with urinary tract infection and voiding dysfunction. Br J Urol. 1997;80:8068.

11. Hoebeke P, Van Laecke E, Van Camp C, Raes A, Van De Walle J. One thousand video-urodynamic studies in children with non-neurogenic bladder sphincter dysfunction. BJU Int. 2001;87:575-80. 
12. Bauer SB, Nijman RJ, Drzewiecki BA, Sillen U, Hoebeke P. International Children's Continence Society standardization report on urodynamic studies of the lower urinary tract in children. Neurourol Urodyn. 2015;34:640-7.

13. Austin PF, Bauer SB, Bower W, Chase J, Franco I, Hoebeke P, Rittig S, Walle JV, von Gontard A, Wright A. The standardization of terminology of lower urinary tract function in children and adolescents: Update report from the standardization committee of the International Children's Continence Society. Neurourol Urodyn. 2016;35:471-81.

14. Swithinbank L, Woodward M, O'Brien M, Frank J, Nicholls G, Abrams P. Pediatric urodynamics: baseline audit and effect on management. J Pediatr Urol. 2005;1:27-30.

15. Lebowitz R, Olbing H, Parkkulainen K, Smellie J, Tamminen-Möbius T. International system of radiographic grading of vesicoureteric reflux. Pediatr Radiol. 1985;15:105-9.

16. Borzyskowski M, Mundy A. Videourodynamic assessment of diurnal urinary incontinence. Arch Dis Child. 1987;62:128-31.

17. Tarcan T, BAUER S, Olmedo E, KHOSHBIN S, KELLY M, DARBEY M. Long-term followup of newborns with myelodysplasia and normal urodynamic findings:: is followup necessary? J Urol. 2001;165:564-7.

18. Sinha S. Follow-up urodynamics in patients with neurogenic bladder. Indian J urology: IJU: J Urol Soc India. 2017;33:267.

19. Theron F, Wilson V, Scriba E, Campbell R, Van Zyl M. (2019) Best practice recommendations for bladder management in spinal cord-afflicted patients in South Africa.

20. Liao L. Evaluation and management of neurogenic bladder: what is new in China? Int J Mol Sci. 2015;16:18580-600.

21. Szabó L, Lombay B, Borbás É, Bajusz I. Videourodynamics in the diagnosis of urinary tract abnormalities in a single center. Pediatr Nephrol. 2004;19:326-31.

22. Reynard J, Lim C, Swami S, Abrams P. The obstructive effect of a urethral catheter. J Urol. 1996;155:901-3.

23. Spinoit A-F, Decalf V, Ragolle I, Ploumidis A, Claeys T, Groen L-A, Van Laecke E, Hoebeke P. Urodynamic studies in children: standardized transurethral video-urodynamic evaluation. J Pediatr Urol. 2016;12:67-8.

24. Janssen K, Deng K, Majerus SJ, Lin DL, Hanzlicek B, Butler RS, van der Vaart CH, Damaser MS. Transurethral versus suprapubic catheterization to test urethral function in rats. Sci Rep. 2021;11:18.

\section{Figures}




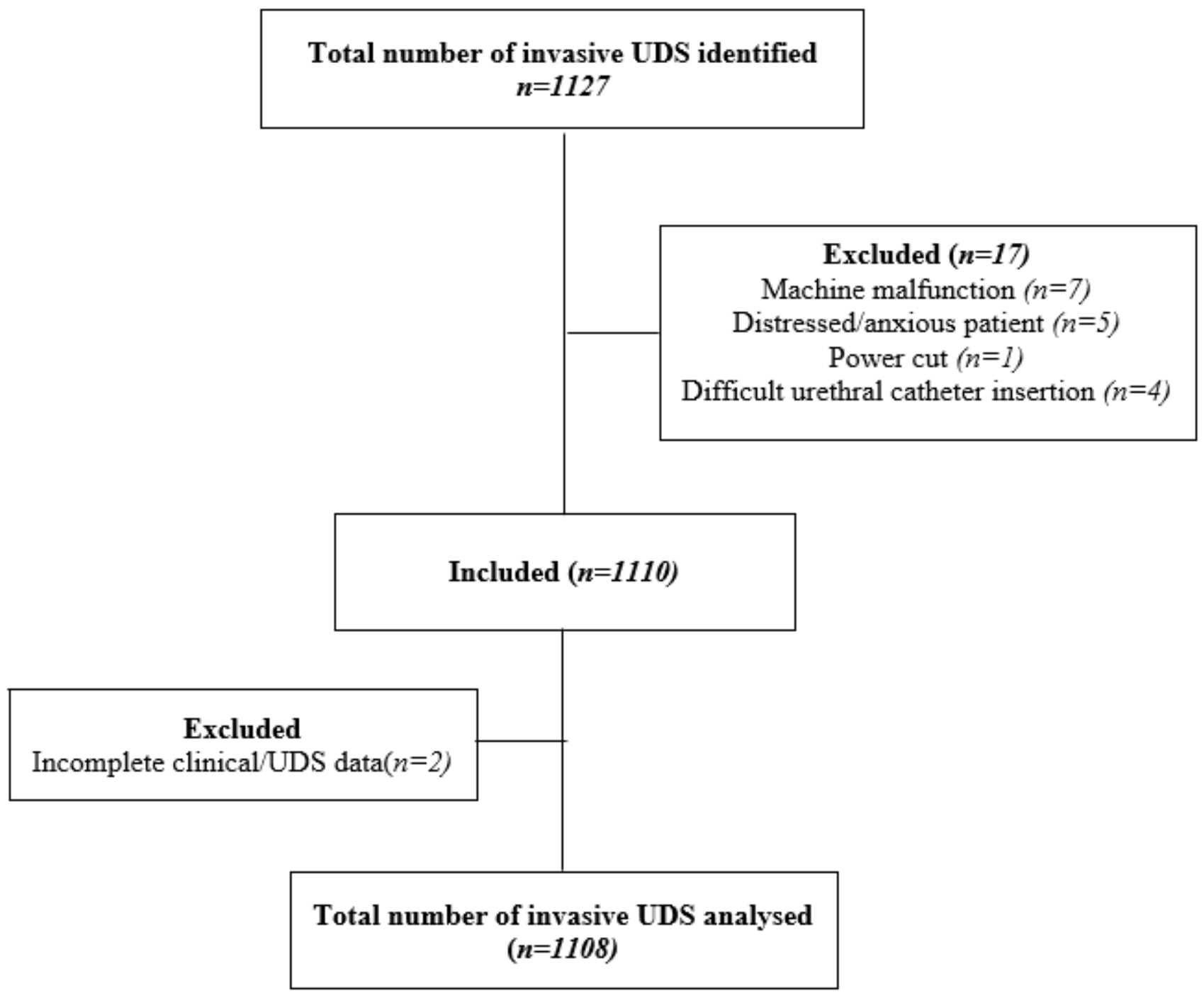

Figure 1

Study flow diagram outlining the sequence of records selection for the study 


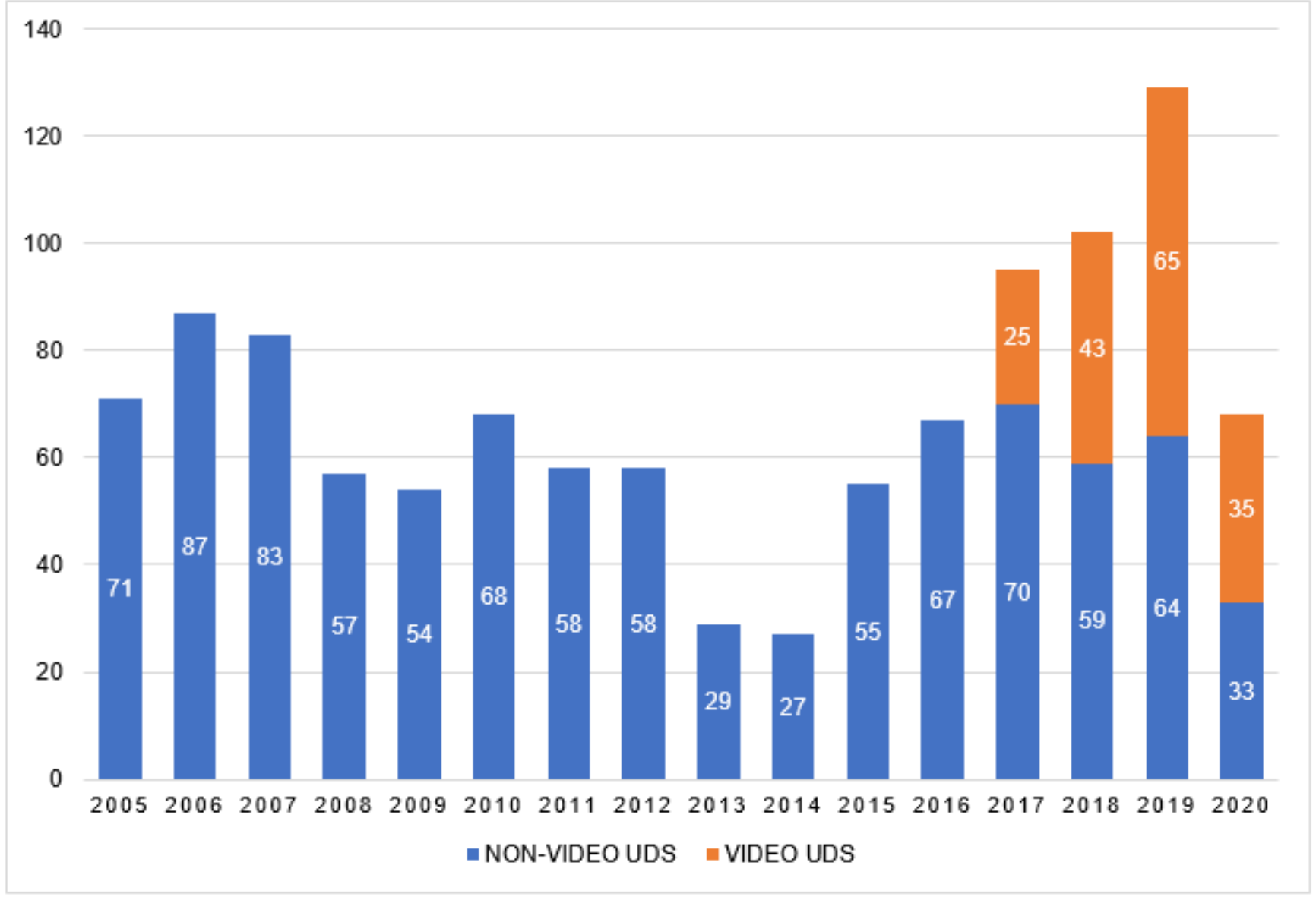

\section{Figure 2}

The number of invasive urodynamic studies performed at Red Cross War Memorial Children's Hospital by year 


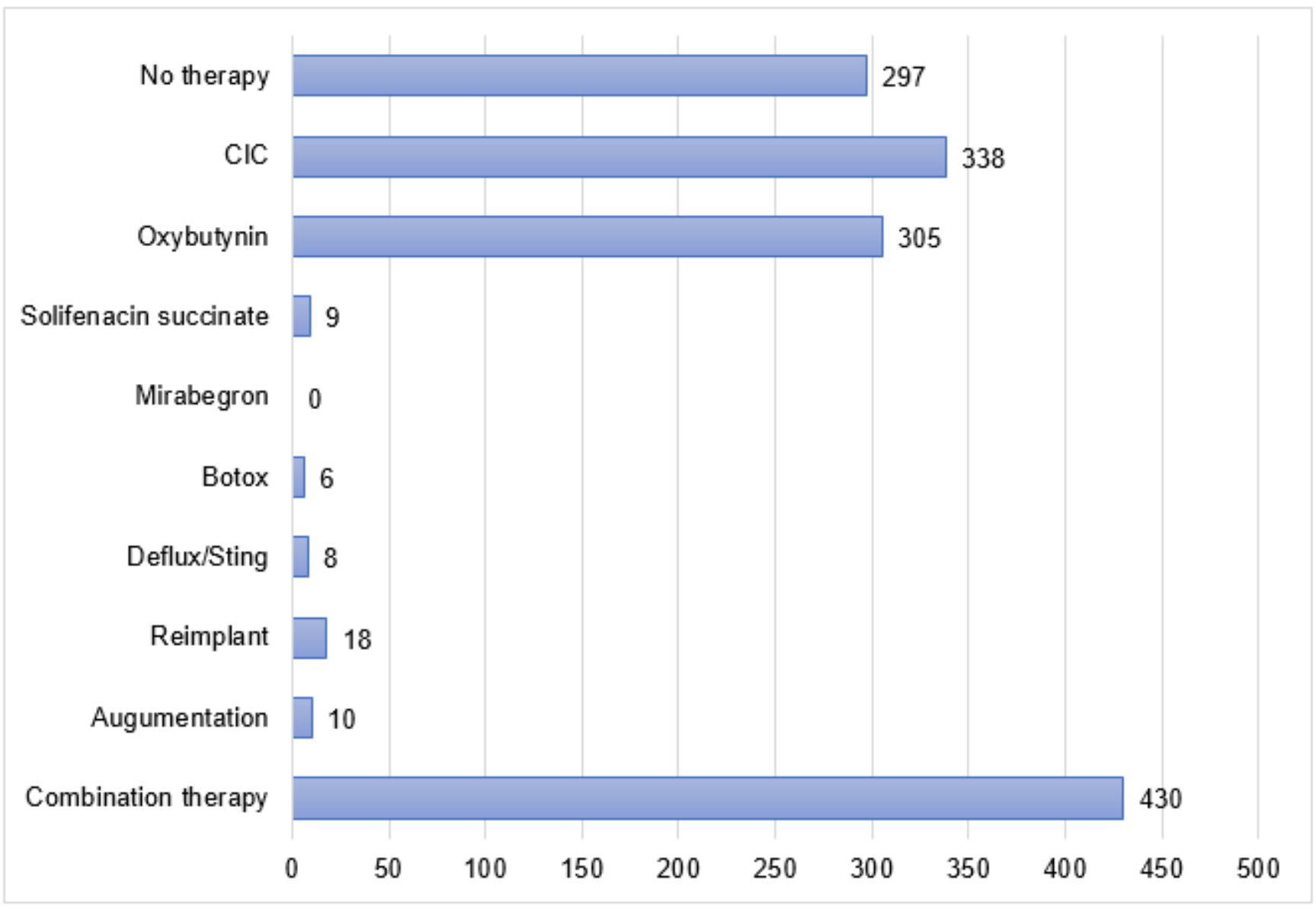

Figure 3

The various types of bladder management at first study ( $n=727$ ) 


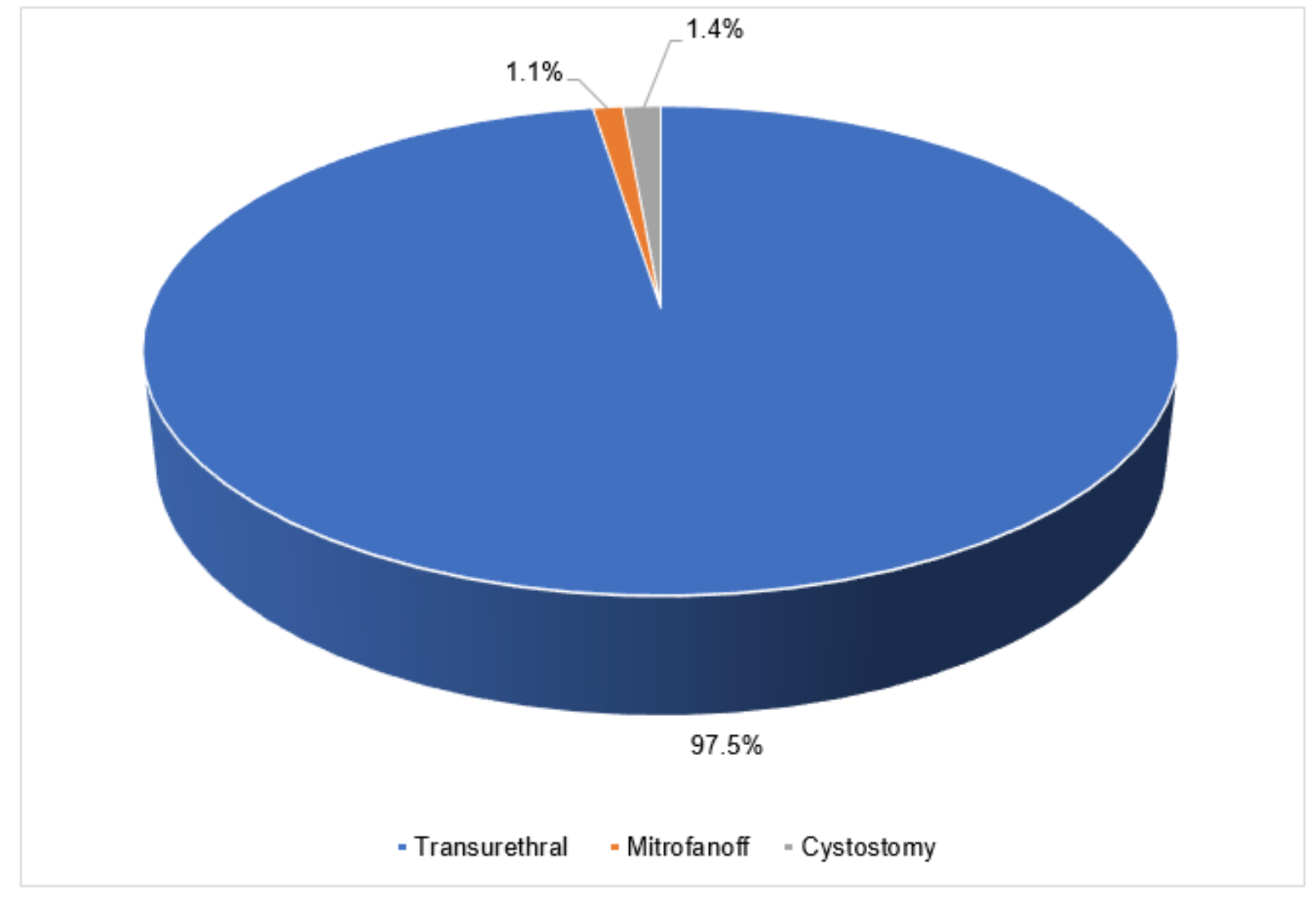

Figure 4

The technique used for bladder catheterisation 


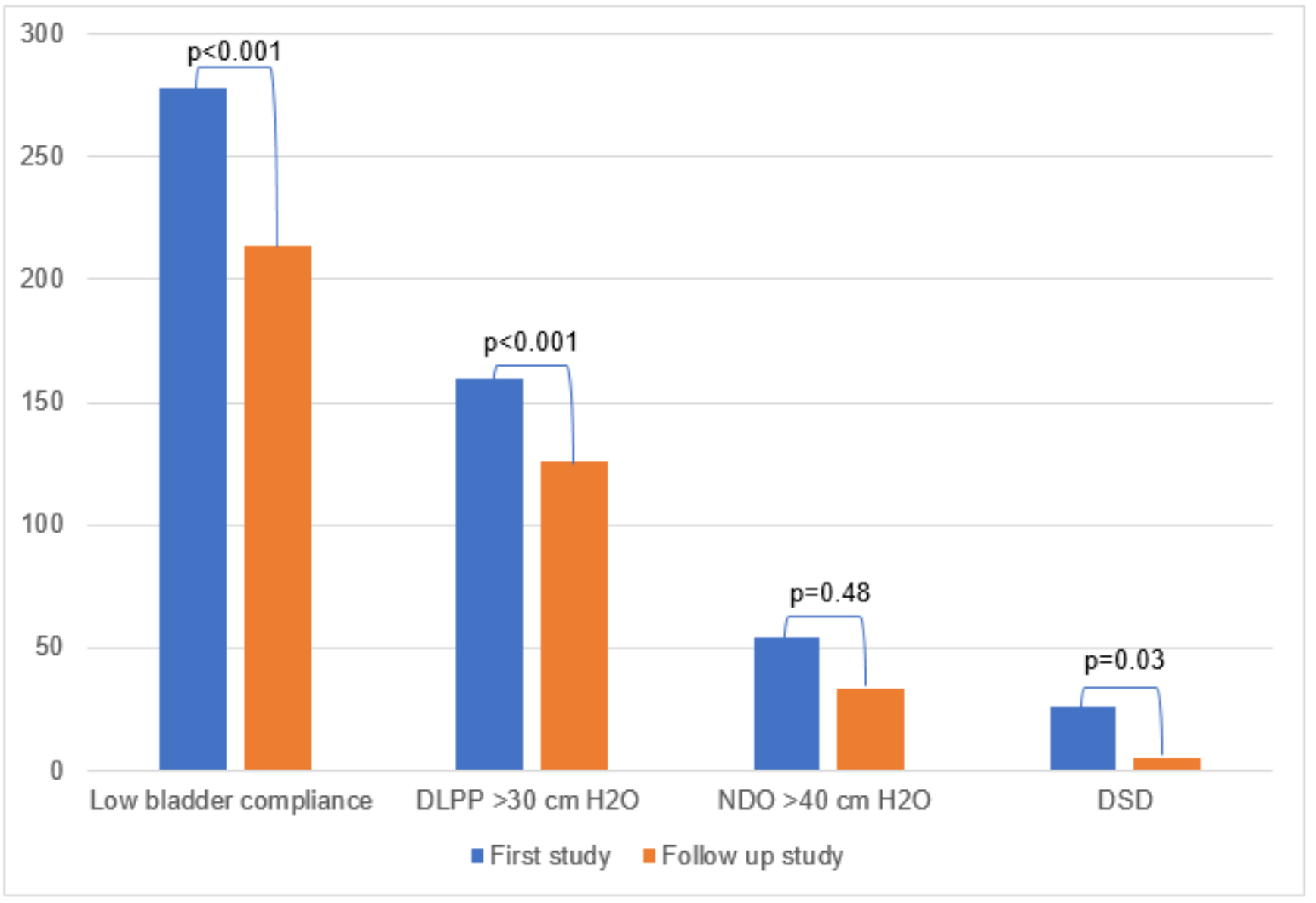

\section{Figure 5}

Comparison of bladder dynamics (high-risk features for upper tract damage) between the first and followup study 